\title{
Distance Education Features using Facebook
}

\author{
https://doi.org/10.3991/ijim.v12i6.9621 \\ Rozhgar Dhyab, Asaf Varol ${ }^{(凶)}$ \\ University of Firat, Elazig, Turkey \\ varol.asaf@gmail.com
}

\begin{abstract}
Thanks to rapid development of information technology there are many new tools that can be used for teaching and learning environment. In the long past, we had met classical classrooms where teachers had to use chalk to write done everything on the blackboard. Later, we have met new tools such as projection, desktop computers, smart boards, etc. in the classical classrooms. Nowadays, we have met with mobile devices. Mobile devices are magic tools which can be used for teaching and learning as a distance. Because of its mobility we do not need to join a classical classroom to listen to courses offered by our teachers any more. Now, we can join in virtual classroom which can be established on cloud. On the other hand, there are many social media applications which can be also used for teaching and learning. For example, it is now possible to teach courses by online where Facebook can be used as a supplementary tool. There are instructors who use Facebook as a learning environment where instructors and learners interact simultaneity on it. The Facebook has made a significant contribution towards solving the problems faced by practical education students during the period of practical education. There is an increasing trend in the study community to use Facebook in order to solve these problems. The aim of this research is to encourage instructors and students to teach and learn by using Facebook as part of a new system of education, namely online distance learning. In this study we explain how mobile devices and social media have been used during teaching and learning of courses at master studies' level at the Department of Software Engineering of College of Technology at Firat University in Turkey. We will explore the advantages and disadvantages of Facebook in terms of teaching and learning environment and we will suggest some recommendations for using Facebook as a teaching and learning platform which have been resulted from our research.
\end{abstract}

Keywords-education, e-learning, Facebook, social networks, web 2.0, learning management system (LMS), communication.

\section{Introduction}

The phenomenon of distance education that employs technological communication techniques in the education process has recently spread across a number of institutes, institutions and universities in a number of different disciplines. Distance learning is characterized by physical separation between students and teachers during the learning process. Distance education that employs technology is known as e-learning, and is 
often utilized by part-time or military personnel, individuals residing in remote areas, and others who are prevented from accessing lecture venues.

As stated in [1], distance education provides a number of advantages for universities and students. Students benefit from the ability to work at any time, while universities benefit from an additional number of students without the need to build more classrooms. Faculty members of many universities believe that the opportunities offered by e-learning are more important than the obstacles. Moreover, the precise arrangements required for e-learning improve their overall teaching skills and their feelings towards their students.

Thus, the challenges posed by the e-learning system are matched by opportunities to reach a larger student audience, meet the needs of students who are unable to attend classroom seminars, and establish a link between students from different social, cultural and economic areas. Facebook is one of the most popular communication tools used for this purpose. The researcher adds his friends and acquaintances to his page, after which people can interact with each other around the world anytime and anywhere, especially when they use smartphones. Some researchers set up a profile on Facebook and studied how it was used, along with its effectiveness in creating an attractive learning environment that enables novice education students to communicate with each other and with their teachers through Facebook as stated in Ref. [2].

As stated in Ref. [3], the integration of Web 2.0 technological platforms such as Facebook into a learning process increases the effectiveness of learning and enhances interaction between students and teachers. Facebook is no longer a social network that requires introduction; neither are its educational uses, which are constantly evolving.

Social networking is simply software designed by skilled and competent people that allows other people to communicate and interact with a particular idea, subject or goal. Social networks are made up of groups of individuals, often called 'friends', who become connected and share ideas. Social networking uses web technologies to connect these individuals together in order to take advantage of the Web's ability to break down time and space barriers.

A group of social networks began to emerge in the late 1990s, such as Classmates.com (established in 1995 to connect alumni) and SixDegrees.com. In 1997, sites began to focus on direct links between people. These sites featured user profiles and private messaging services for groups of friends. Although these early sites provided services similar to those found in contemporary social networks, they were unable to generate profits for their owners and have since been shut down as mentioned in Ref. [4].

'The Facebook', which launched in 2004, was a network open to all college and high school students as an alternative to MySpace with its millions of users. Over time, this led to a significant increase in the number of Facebook users as stated in [5]. Facebook is not only one of the most famous social networking sites but one of the most popular websites overall; it is the second most famous site in the world, and was ranked ninth among the top 100 tools of learning in 2013. As shown in figure 1, the number of active Facebook users as of April 2018 was about 2.2 billion as given in Ref. [6]. Given the importance of this site and its widespread reach, it is important to consider the need to 
use social networking media, especially Facebook, for educational purposes. This strategy is being used very intensely among young people, and it has also been mentioned that there has been great interest and significant development in the use of social networks by educational institutions in support of the teaching and learning process.

Social networking has become a subject of study for many scholars and researchers. This work touches on a number of topics, such as privacy, identity, community capital and, finally, e-learning. Fig. 2 shows some examples of the use of social networks (in this case, Hangouts and Facebook) for educational purposes.

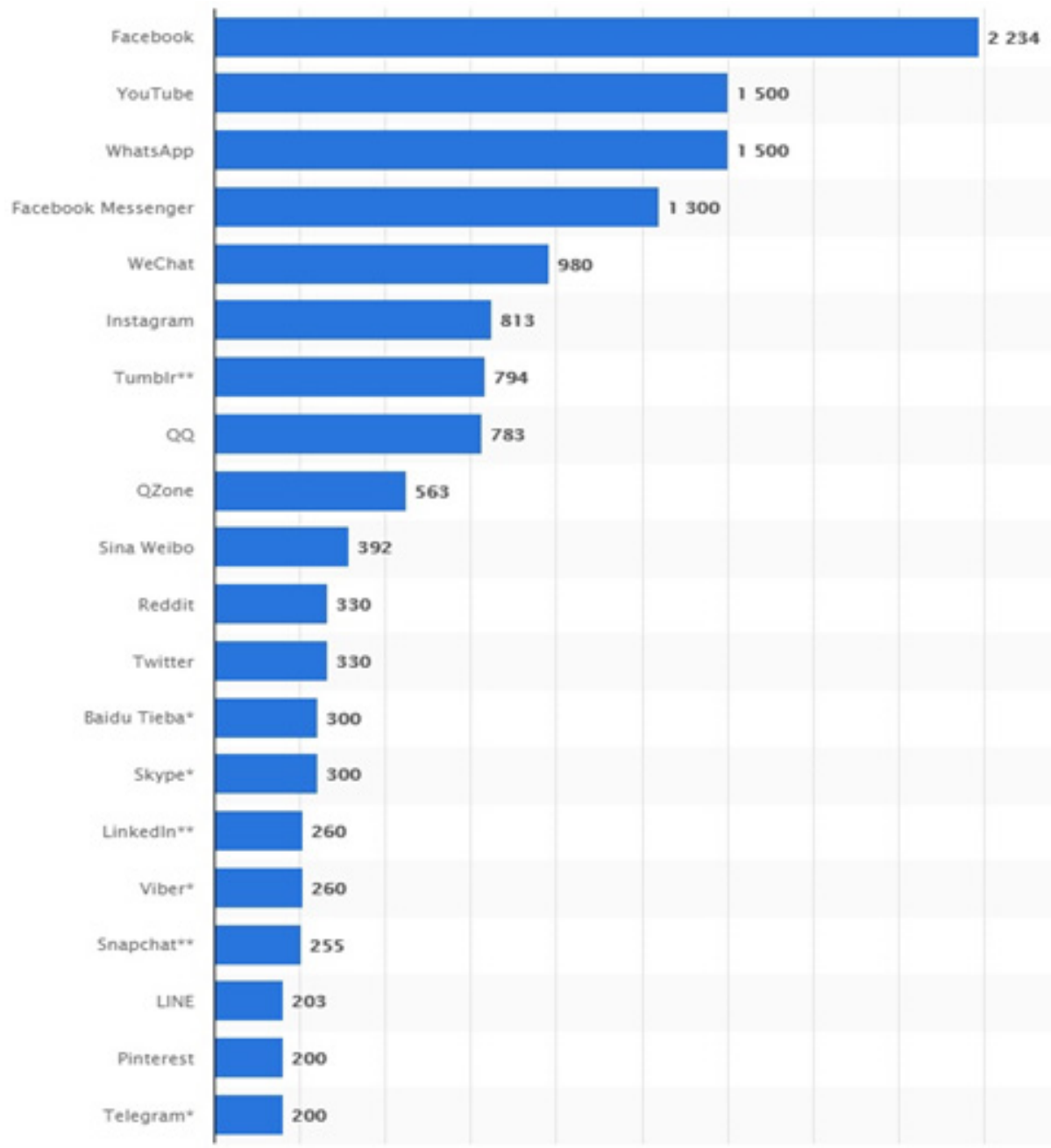

Fig. 1. User Chart Active in Social Networking in April 2018. 


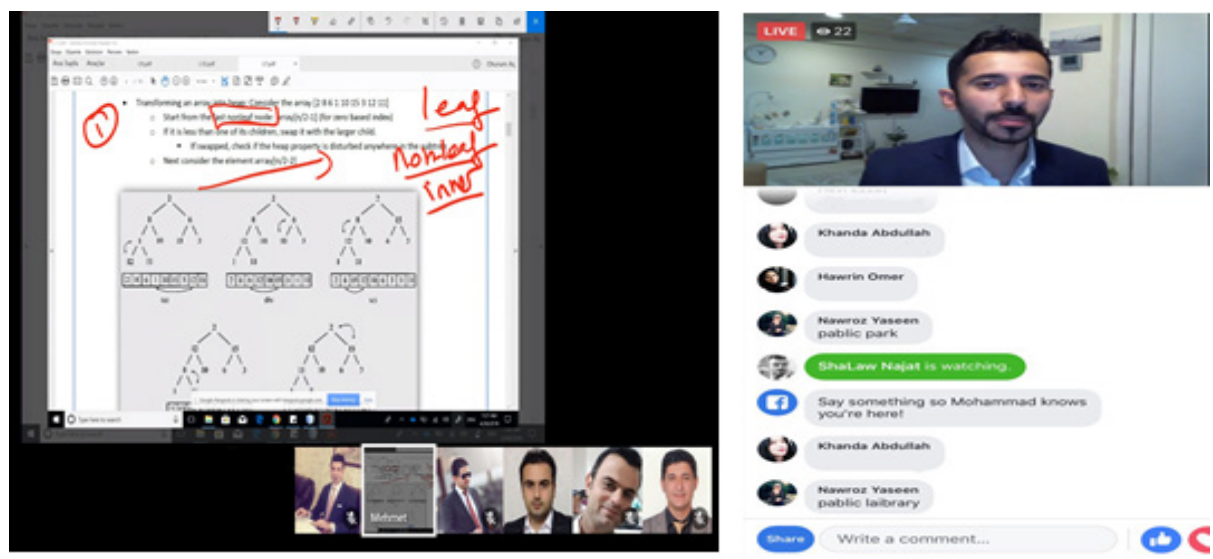

Fig. 2. Some of the images are from social networks (Hangouts and Facebook) during education.

\section{Facebook in education}

Technology such as Facebook can be incorporated into modern learning methods to help students communicate at anytime and anywhere, as well as to help them interact with their teachers. This method positively affects the student's relationship with the teacher and increases the cooperative activities in the classroom. Integrating Web 2.0 technology such as Facebook into teaching may enhance student skills in writing, reading, listening and conversation as stated in [5]. For example, on one Facebook page created to teach the English language, all participants were asked to write sentences using information concluded from watching a video, then share them with their fellow students and read each other's work. Here, the students used a new technique that made it easy to communicate with the teacher and foster a good relationship with their friends when they shared their work. Moreover, Facebook makes it easier to understand new information about a student. The teacher can also add video, images or mental maps to facilitate understanding of complex concepts he or she has presented in class, and students can create discussion groups with each other as stated in Ref. [7].

Facebook offers tremendous potential for teachers, students, parents and administrators. These groups can leverage the platform and invest in improving teaching and learning to ensure stronger and better communication and better educational outcomes, create a special group or page related to an educational subject, and invite students to participate in the exchange of information and ideas, as well as disseminate and exchange links to websites, pages, videos, pictures and other material related to the subject or article. Also, in this way, students and young people may recognize other uses of Facebook that are more useful and effective. For these reasons and other reasons that we will explain later, Facebook is more service-oriented than education-oriented, as seen in fig. 3 which is given in Ref. [8]. Therefore, the use of Facebook in the process of education is not easy; however, it is necessary to conduct various processes and arrangements in order to facilitate the use of this technology for social and educational 
purposes, along with providing a systematic basis for its effective use in education. Facebook has created an environment that encourages learning and fosters teacher-student relationships and interaction. It is also an innovative way to develop social and cultural awareness. In general, social networking sites like Facebook are worth pursuing as educational tools as stated in [9].

There may be many ways in which we can use Facebook in education and in classrooms. However, before you start using this social network, which is designed primarily for sharing, it is important to take a look at some specific considerations. For example, understanding things such as social media and privacy concerns will help you ensure that your students enter a secure virtual space. Helping students understand their digital footprint remains an important goal as stated in [10].

Why use Facebook in education? To answer this question, we may recall some of its strengths:

- Its status as a communication and interaction environment that is not limited to a specific time or place.

- Simple, free and easy to use.

- Encourages active and positive student participation.

- Suitable for a range of different student age groups.

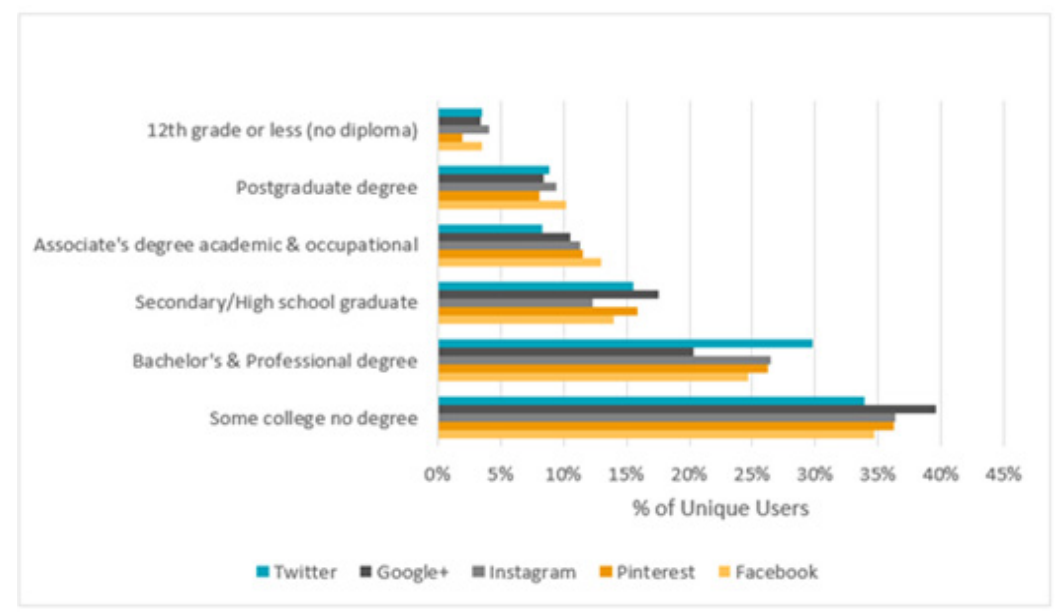

Fig. 3. Education levels of social media users

\section{$3 \quad$ Facebook and learning management system (LMS)}

The learning management system (LMS) is one of the most important components of e-learning as mentioned in [11]. It is an integrated system responsible for managing the educational process via the Internet. The system includes admission to and registration in courses, course management and follow-up of student learning, assignments, and supervision of both contractual and non-communicative communication tools, email, discussion forums, and test management as stated in Ref. [12]. 
Electronic learning systems such as blackboards are an appropriate means of managing and practicing e-learning systematically in the web 2.0 context. However, when taking social networks as a means of sharing information and communicating with others, it may emerge that e-learning systems do not provide enough flexibility and control over students' learning as stated in Ref. [13].

E-learning management systems suffer from the problem of low user interaction. Interaction between users can be increased by integrating e-learning systems with social networks. When Coome LMS was integrated with the Facebook platform, Facebook was found to be an effective way to discuss course topics compared to the WebCT Forum, and participation in the Facebook-linked condition was much greater than for the participants in the WebCT forum as stated in $[14,15]$.

Students felt comfortable using Facebook groups as an alternative to learning management systems and stated that they wanted to use Facebook groups in other courses in the future; clarification on this issue is presented in Table I which is given in [16]. The Facebook group is not only an alternative to learning management systems, but also has other key advantages, such as promoting collaborative learning and active learning. Some drawbacks also emerged, such as the dynamic movement of group activities by some students in the group. However, it would appear that Facebook groups can be used effectively as a learning management system and work to enhance the skills of the 21 st century learner as stated in [17].

Table 1. Difference between LMS and Facebook groups

\begin{tabular}{|c|c|c|}
\hline Property & Learning Management Systems & Facebook Groups \\
\hline Ownership & $\begin{array}{l}\text { Supervised by an educational institu- } \\
\text { tion }\end{array}$ & $\begin{array}{l}\text { Not supervised by an organization or by students } \\
\text { (neutral). This may be perceived as a negative in } \\
\text { terms of privacy, content, and backup }\end{array}$ \\
\hline Costs & $\begin{array}{l}\text { Not free/May be free, but requires } \\
\text { constant maintenance }\end{array}$ & Free and does not need maintenance \\
\hline Logging in & $\begin{array}{l}\text { The institution creates a username and } \\
\text { password, which the student is forced } \\
\text { to use }\end{array}$ & $\begin{array}{l}\text { The student can use his or her personal account } \\
\text { to access Facebook groups }\end{array}$ \\
\hline $\begin{array}{l}\text { Creating and } \\
\text { sharing content }\end{array}$ & $\begin{array}{l}\text { Provides powerful tools for creating } \\
\text { and storing a wide range of content, } \\
\text { such as presentations }\end{array}$ & $\begin{array}{l}\text { Recently, Facebook groups have allowed for files } \\
\text { of up to } 25 \mathrm{MB} \text { to be uploaded or downloaded } \\
\text { via Dropbox }\end{array}$ \\
\hline $\begin{array}{l}\text { Content man- } \\
\text { agement }\end{array}$ & $\begin{array}{l}\text { The teacher has permission to create, } \\
\text { publish, and delete content }\end{array}$ & $\begin{array}{l}\text { In most cases, there is a similarity between } \\
\text { teacher and student permissions when creating } \\
\text { and deleting content }\end{array}$ \\
\hline $\begin{array}{l}\text { Organizing con- } \\
\text { tent }\end{array}$ & Controlled by the teacher & $\begin{array}{l}\text { Not controlled by the teacher; dynamic, in that } \\
\text { new posts and comments appear at the top }\end{array}$ \\
\hline $\begin{array}{l}\text { Relationship be- } \\
\text { tween content } \\
\text { and interaction }\end{array}$ & $\begin{array}{l}\text { A teacher can create content such as a } \\
\text { presentation or interaction as on a fo- } \\
\text { rum, but each is separate from the } \\
\text { other }\end{array}$ & $\begin{array}{l}\text { All interactions and content are created in the } \\
\text { status bar, where any item is automatically added } \\
\text { to the status bar }\end{array}$ \\
\hline Evaluation tools & $\begin{array}{l}\text { Many evaluation tools available such } \\
\text { as multiple-choice questionnaires and } \\
\text { reports on activities, tasks and tests }\end{array}$ & $\begin{array}{l}\text { Facebook groups do not have many of these } \\
\text { tools, but you can take advantage of some appli- } \\
\text { cations or integrate with other tools such as } \\
\text { Google Drive etc. }\end{array}$ \\
\hline
\end{tabular}




\section{$4 \quad$ Education features using Facebook}

There are many Facebook features used by teachers in different disciplines. Some Facebook features that will help you to take advantage of Facebook's benefits, thus making both teaching and learning more effective, are presented below:

\subsection{Cooperative learning}

As stated in [18], Facebook is both an opportunity and a highly appropriate tool for teachers to invest in supporting collaborative learning. Students are divided into groups, each of which is available on a Facebook page or a group on their own. The members of each group coordinate through the same network to accomplish the tasks they are assigned, whether this is research, providing answers or something else. We note that this method also fits project-based learning.

\subsection{Take advantage of the places tool}

This tool presents an opportunity to encourage learners to deal with maps, such as locating nearby places and even neighboring countries as stated in [19].

\subsection{Communicate and learn about new things}

As a leading social networking site, as well as a great forum for discussion, dialogue and cross-cultural encounters with different languages and customs, Facebook offers tremendous potential for teachers, students, parents and administrators to leverage and improve teaching and learning.

\subsection{Advertising}

As stated in Ref. [20, 21], Facebook can be very easily used as a tool and means of advertising. For example,

- Inviting students (and others) to attend various educational events, such as lectures, meetings and formations;

- Postponing tests;

- Requesting a duty or task assignment;

- Summarizing important points within the lesson.

\subsection{Take advantage of the events tool}

This is a feature provided by Facebook through which the teacher can alert group members to (for example) a test date, the date on which a certain exercise will be held, or the time of completion of a task. 


\subsection{Support modern teaching strategies}

Like many other networks, Facebook provides an opportunity to diversify the teaching methods and learning platforms through which many modern teaching strategies can be used, e.g. problem-solving, project-based learning, brainstorming, discovery learning, etc. in stated in $[22,23]$.

\subsection{Brainstorming tool}

The teacher asks students to present their ideas and information about a particular topic or project so that they can be utilized later in the course.

\subsection{Follow up developments}

Teachers on Facebook can stay up to date on their specialty, as well as stay in touch with colleagues from around the world.

\subsection{Facebook educational applications}

The site provides a large number of educational games and applications, which are recommended to employ in order to entice students to study and make access to learning more fun as stated in Ref. [24].

\subsection{Sharing and exchange of information}

As mentioned [25, 26], in Facebook has enormous technological potential for the sharing and exchange of information; for example, consider the following:

- Publishing educational images and videos appropriate to the material and sharing these with students and other interested people, who can comment on them and discuss their content.

- Exchanging experiences and information with other interested people from all over the world on a specific educational subject.

- Publishing and sharing e-books (using a new Facebook page as a template).

- Publishing and sharing useful websites and media to enhance students' depth of available information and broaden their horizons.

\subsection{Motivate students and develop motivation towards learning}

Facebook's strengths, potentials and tools will inevitably contribute to driving student motivation. This is essential in any effective learning process, as it encourages more effort, interaction and communication, which will lead to positive learning outcomes. 


\subsection{Feedback}

Feedback is of great importance to learners. They are required to answer using correct information and correct it if it is wrong, and Facebook is a very appropriate tool for this; whether through comments, posts or admiration, Facebook sustains communication (synchronous and asynchronous), which affects students positively as mentioned in Ref. [27, 28].

\subsection{Communicate with parents}

The importance of communication between educators and parents is no secret. We have noted this more than once on the blog, addressing its importance and highlighting the most important means and tools to facilitate this communication. Facebook is one of these, and can be employed to;

- Share videos, photos and activities;

- Request opinions;

- Send invitations to attend events.

\subsection{Voting and opinion polls}

The opinions of students on a given topic may vary. To promote discussion and open debate, which should prevail in our classrooms to increase communication, the teacher can use the voting feature provided by Facebook as stated in [29].

\subsection{Collaborative Research}

Students and teachers can review research together by sending it to students in the same discipline for their perusal. The teacher can then ask students to write up what they have learned from the research on Facebook; for example, groups of students looking at specific topics can be created in.

\subsection{LMS learning systems}

Take advantage of Facebook's ability to be used together with many other tools; for example, it can be integrated into LMS learning systems, such as Blackboard, Schoology, ILIAS or Moodle. This method enables learners to follow publications and messages on their personal pages as stated in [30].

Firat University, Software Engineering Department offers diplomas of Master and $\mathrm{PhD}$ degrees. There are many foreign students contributing from Pakistan, Jordan, Nigeria, Syria, Iraq, Somalia, Afghanistan, Iran, America, etc. to follow courses as a distance. We use two different platforms, namely Firat LMS as shown in Fig. 4 and Schoology as shown in Fig. 5 for teaching courses as a distance. 


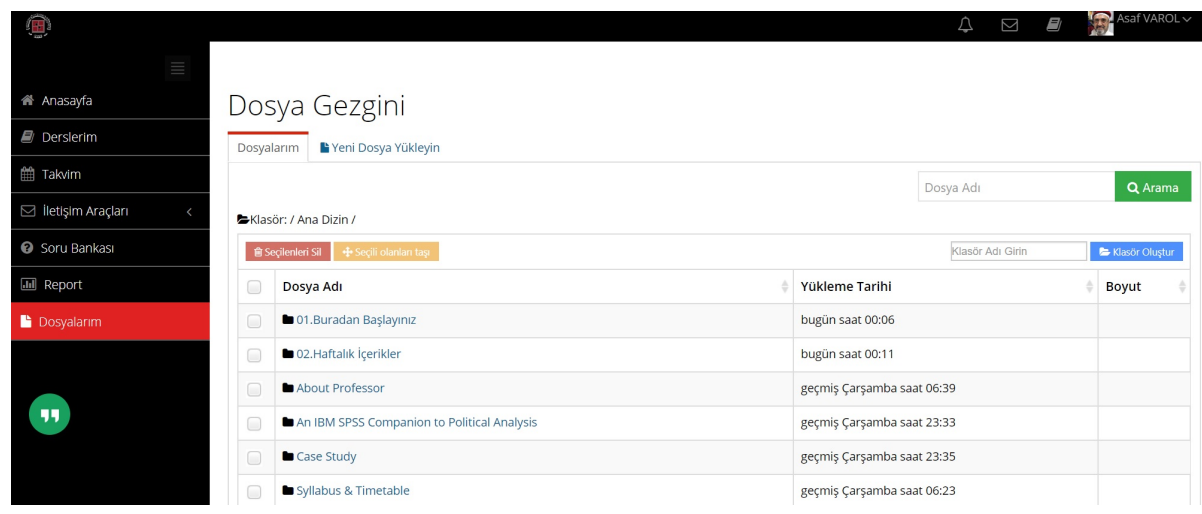

Fig. 4. LMS platforms which is used for the Scientific Research Methods Course offered by Software Engineering Department.

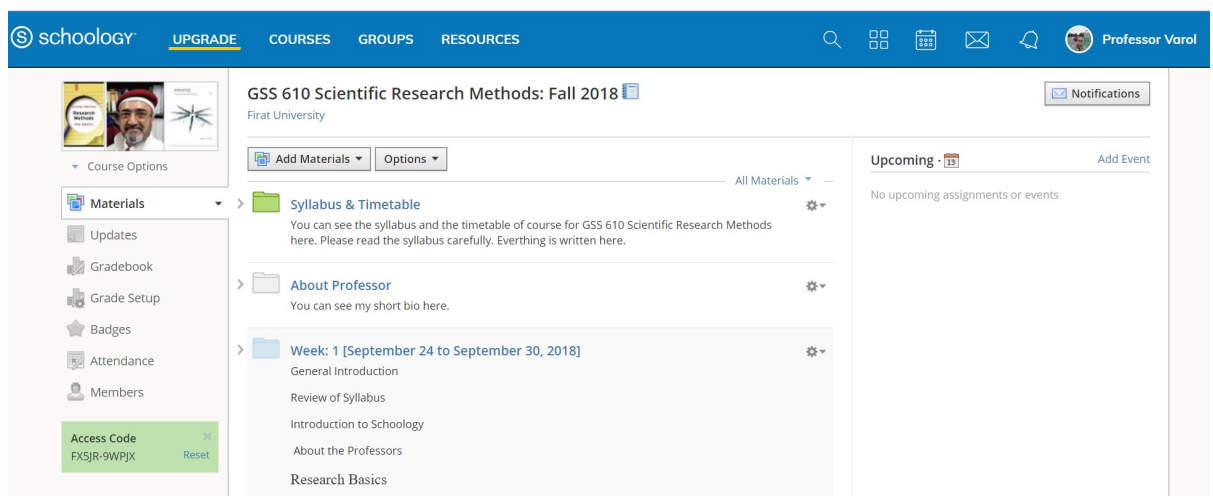

Fig. 5. Firat University Software Engineering Department offers distance courses using Schoology Platform.

We also utilize Hangouts and Facebook as additional communication tools during synchronous online teaching. Particularly, students join these platforms for discussion sessions conducted for the class topics, live presentations, office hours meeting with the course instructor, etc.

\section{$5 \quad$ Education way to use Facebook}

There are many different ways in which teachers in different disciplines can utilize Facebook, including the following:

- Inculcate students' ambition and increase their motivation by encouraging them to create and design new applications on Facebook that present educational material and disseminate it among other learners, who may benefit from it; in this way, many students can present their practical applications as stated in [27]. 
- Challenge participation: The teacher can engage students in activities that demonstrate their abilities and talents; for example, the preparation of graduation projects, or promotion of their educational institution.

- Create a special page for the course, invite students to it, and determine the validity of the page views. Students' contributions and interactions can enrich course topics. Students can also take advantage of the Status Tool, the Photo and Video tools, and the tools for events as in Facebook groups.

- Teaching other languages: Students can communicate with other native speakers of (for example) English or French through groups or networks as stated in [31].

- Multimedia: The teacher can prepare videos or other multimedia tools and send them out to students to facilitate learning as mentioned in [32].

- Educational games: These can be used to improve students' reading and writing skills which is stated in Ref. [33].

- Take advantage of the question-asking tool by asking specific questions or creating a poll on an issue. This tool will show the participants' answers as well as their names as stated in Ref. [34].

- Use the 'like' or 'comment' tool to provide immediate feedback on a topic or answer, which leads to the strengthening of students' answers.

- Utilize the participation tool to share information relevant to the subject within the course group.

- Use the file upload menu to upload any files that the teacher wants to share with students; these can be either uploaded directly or previewed if desired.

- Students can record an explanation of a program or particular certain steps (such as steps to access system recovery) through a screen recording program, then share the results with the course group so that students will benefit from it. These resources can later act as a reference when needed as stated in [35].

\section{Positive elements of education using Facebook}

There are some positive aspects of using Facebook as an educational tool:

- After each lesson, the teacher can use Facebook to add annotations, notes, or reviews that he or she could not add at the time of the lesson.

- Students' opinions on a particular subject may differ and require a decision. In this case, in keeping with the spirit of democracy that should prevail in our classrooms, and in order to increase communication, the teacher can make use of the voting feature provided by Facebook.

- Students can comment on an image, publication, or video related to a particular lesson. This feature can be used to identify learner representations of specific educational content that the teacher may be preparing.

- Facebook is a useful tool for both the self-development and satisfaction of student needs and can increase student confidence as stated in [36].

- Facebook is a free communication tool where a student or teacher can easily create a study page and exchange information. 
- Facebook is a great forum for dialogue and discussion, acting as a social center because it serves users from multiple cultures, along with their different languages and customs as stated in Ref. [37].

- Users can make friends and from relationships with people from around the world who are interested in a particular subject or theme and exchange information and experiences with them.

- Enables expansion of the circle of learners by facilitating easy communication between the learners and the teacher as mentioned in [38].

- Allows for dissemination of technical culture and expands students' perceptions of the latest developments in their field of study.

- Gives some students, who may be too embarrassed to interact with the teacher directly, the opportunity to present their views in writing, which may assist them to participate as stated in [39].

- Presents social and economic benefits by reduce spending on classrooms, university buildings, instruments and other teaching methods, as well as reducing traffic density in city streets and promoting the preservation of the environment by decreasing paper use and printing as stated in [40].

- By encouraging communication and interaction between intellectuals from different environments, helps to activate learners' skills, provides an opportunity for them to learn, increases their ability, and motivates them to think creatively and in different ways and methods as indicated in [41].

\section{$7 \quad$ Negative elements of education using Facebook}

However, there are also some negative aspects of using Facebook as an educational tool:

- The absence of audio and visual communication between the teacher and the student members of the group. Being limited to only written communication may create a state of boredom in some students and reduce their motivation to learn.

- The lack of coordination in the process of responses, which may cause some confusion and misunderstanding among some as stated in [42].

- The presence of external influences that may distract some students, such as the presence of some ads or notification alerts that can hinder the student's learning process as mentioned in [43].

- The possibility that it might become difficult to reliably ascertaining the students' true personality during the dialogue; this may lead to the incorrect evaluation of students' learning outcomes as stated in 44].

- Increasing the number of hours students spend in front of the computer may lead to some psychological or social problems. 


\section{Conclusion}

There has been tremendous progress in technology and social networks, creating the need to think about new and innovative teaching methods in order to keep abreast of these developments and meet the requirements of the student or learner who is ambitious about attaining knowledge of technology. From the above, through our findings, the teacher is encouraged to implement means of social communication, as they have a clear impact on interaction and the exchange of views, discussions, and experiences of the subject matter. This technology is fun, easy to use and available everywhere. Hence, we draw the attention of schools and universities towards the use of Facebook and Hangouts in education, due to its many positive aspects that have opened up a wider scope for the exchange of knowledge among its users; however, we also recommend using Facebook in a useful and effective way and maintaining established values and behaviors.

Social networks are not simply sites for identifying new friends or learning what is happening around the world; they can also be amazing learning tools if used effectively. Social networks have proven to be of great use in teaching, as they can integrate students into effective activities and provide the potential for more useful and valuable uses.

Only some of the possible methods have been outlined here; there are still more to come. Some people think that social networking platforms will become a complete substitute for traditional e-learning programs in the near future, which could dramatically change the concept of e-learning.

The above methods and ideas are not only important for the utilization of Facebook as an educational tool; ideas are, after all, difficult to define. Creativity is always an open and ongoing process, especially in light of the rapidly developing technology that surrounds us on all sides.

\section{$9 \quad$ References}

[1] Uden, L., Wangsa, I.T. and Damiani, E., 2007, February. The future of E-learning: E-learning ecosystem. In Digital EcoSystems and technologies conference, 2007. DEST'07. Inaugural IEEE-IES (pp. 113-117). IEEE.

[2] Ractham, P. and Firpo, D., 2011, January. Using social networking technology to en-hance learning in higher education: A case study using Facebook. In System Sciences (HICSS), 2011 44th Hawaii International Conference on (pp. 1-10). IEEE.

[3] Vassileva, J., 2008. Toward social learning environments. IEEE transactions on learn-ing technologies, 1(4), pp.199-214. https://doi.org/10.1109/TLT.2009.4

[4] Deparis, E., Abel, M.H., Lortal, G. and Mattioli, J., 2013, June. Designing a system to capitalize both social and documentary resources. In Computer Supported Coopera-tive Work in Design (CSCWD), 2013 IEEE 17th International Conference on (pp. 581-586). IEEE.

[5] Ouf, S., Nasr, M. and Helmy, Y., 2010, December. An enhanced e-learning ecosystem based on an integration between cloud computing and Web2. 0. In Signal Processing and Information Technology (ISSPIT), 2010 IEEE International Symposium on (pp. 48-55). IEEE. 
[6] Siikanen, M., Baltakys, K., Kanniainen, J., Vatrapu, R., Mukkamala, R. and Hussain, A., 2018. Facebook drives behavior of passive households in stock markets. Finance Research Letters. https://www.statista.com/statistics/272014/global-social-networks-ranked-by-number-of-users/

[7] Navarro, C.X., Molina, A.I., Redondo, M.A. and Juárez-Ramírez, R., 2016. Framework to evaluate m-learning systems: A technological and pedagogical approach. IEEE Re-vista Iberoamericana de Tecnologias del Aprendizaje, 11(1), pp.33-40. https://doi.org/10.1109/RI TA.2016.2518459

[8] Bicen, H. and Uzunboylu, H., 2013. The Use of Social Networking Sites in Education: A Case Study of Facebook. J. UCS, 19(5), pp.658-671. https://www.postplanner.com/blog/wtf-grow-followers-wrong-social-platform/

[9] Michalik, P., Stofa, J. and Zolotova, I., 2014, January. Concept definition for Big Data architecture in the education system. In Applied Machine Intelligence and Informatics (SAMI), 2014 IEEE 12th International Symposium on (pp. 331-334). IEEE.

[10] Helser, S., 2011, May. An interdisciplinary approach to address identity theft educa-tion. In Technology and Society (ISTAS), 2011 IEEE International Symposium on (pp. 1-8). IEEE.

[11] Kumar, S., Gankotiya, A.K. and Dutta, K., 2011, April. A comparative study of moo-dle with other e-learning systems. In Electronics Computer Technology (ICECT), 2011 3rd International Conference on (Vol. 5, pp. 414-418). IEEE.

[12] Bouboulis, P., Theodoridis, S. and Mavroforakis, M., 2012. The augmented complex kernel LMS. IEEE Transactions on Signal Processing, 60(9), pp.4962-4967. https://doi.org/10.1109/TSP.2012.2200479

[13] Yen, N.Y., Shih, T.K., Chao, L.R. and Jin, Q., 2010. Ranking metrics and search guid-ance for learning object repository. IEEE transactions on Learning Technologies, 3(3), pp.250264. https://doi.org/10.1109/TLT.2010.15

[14] Caminero, A.C., Ros, S., Robles-Gómez, A., Tobarra, L., Hernández, R., Pastor, R., Rodríguez-Artacho, M., San Cristóbal, E., Martín, S. and Tawfik, M., 2012, October. Work in progress: Extending a LMS with social capabilities: Integrating Moodle into Facebook. In Frontiers in Education Conference (FIE), 2012 (pp. 1-2). IEEE.

[15] Baggs, R. and Wu, C.W., 2010, August. Exploration of asynchronous online teaching with a network analysis of class interaction. In Social Computing (SocialCom), 2010 IEEE Second International Conference on (pp. 355-362). IEEE.

[16] Said, M.N.H.M., Tahir, L.M. and Ali, M.F., 2014, April. Facebook as a tool: Exploring the use of Facebook in teaching and learning. In Teaching and Learning in Computing and Engineering (LaTiCE), 2014 International Conference on (pp. 120-124). IEEE.

[17] Miron, E. and Ravid, G., 2015. Facebook Groups as an Academic Teaching Aid: Case Study and Recommendations for Educators. Journal of Educational Technology \& Society, 18(4).

[18] Farahbakhsh, R., Han, X., Cuevas, A. and Crespi, N., 2013, August. Analysis of pub-licly disclosed information in facebook profiles. In Advances in Social Networks Analysis and Mining (ASONAM), 2013 IEEE/ACM International Conference on (pp. 699-705). IEEE.

[19] Lockyer, L. and Patterson, J., 2008, July. Integrating social networking technologies in education: a case study of a formal learning environment. In Advanced Learning Technologies, 2008. ICALT'08. Eighth IEEE International Conference on (pp. 529-533). IEEE.

[20] Korolova, A., 2010, December. Privacy violations using microtargeted ads: A case study. In Data Mining Workshops (ICDMW), 2010 IEEE International Conference on (pp. 474-482). IEEE.

[21] Gusev, M., Ristov, S., Velkoski, G., Guseva, A. and Gushev, P., 2014, November. Scalable architecture of alert notification as a service. In Information Society (i-Society), 2014 International Conference on (pp. 80-85). IEEE. 
[22] Yang, Q., Zhou, Z.H., Mao, W., Li, W. and Liu, N.N., 2010. Social learning. IEEE Intelligent Systems, 25(4), pp.9-11. https://doi.org/10.1109/MIS.2010.103

[23] Yang, S., Kavanaugh, A., Kozievitch, N.P., Li, L.T., Srinivasan, V., Sheetz, S.D., Whalen, T., Shoemaker, D., da S Torres, R. and Fox, E.A., 2011, June. CTRnet DL for disaster information services. In Proceedings of the 11th annual international ACM/IEEE joint conference on Digital libraries (pp. 437-438). ACM.

[24] Widrow, B., Gupta, N.K. and Maitra, S., 1973. Punish/reward: Learning with a critic in adaptive threshold systems. IEEE Transactions on Systems, Man, and Cybernetics, (5), pp.455-465. https://doi.org/10.1109/TSMC.1973.4309272

[25] Dhami, A., Agarwal, N., Chakraborty, T.K., Singh, B.P. and Minj, J., 2013, February. Impact of trust, security and privacy concerns in social networking: An exploratory study to understand the pattern of information revelation in Facebook. In Advance Computing Conference (IACC), 2013 IEEE 3rd International (pp. 465-469). IEEE.

[26] McDaniel, R., Lindgren, R. and Friskics, J., 2012, October. Using badges for shaping interactions in online learning environments. In Professional Communication Confer-ence (IPCC), 2012 IEEE International (pp. 1-4). IEEE.

[27] Fovet, F., 2009, October. Impact of the use of Facebook amongst students of high school age with Social, Emotional and Behavioural Difficulties (SEBD). In Frontiers in Education Conference, 2009. FIE'09. 39th IEEE (pp. 1-6). IEEE.

[28] de Zwart, M., Henderson, M., Phillips, M. and Lindsay, D., 2010, June. 'I like, stalk them on Facebook': Teachers"privacy'and the risks of social networking sites. In Technology and Society (ISTAS), 2010 IEEE International Symposium on (pp. 319-326). IEEE.

[29] Galbrun, E. and Miettinen, P., 2016, December. Analysing political opinions using redescription mining. In Data Mining Workshops (ICDMW), 2016 IEEE 16th Interna-tional Conference on (pp. 422-427). IEEE.

[30] Goth, G., 2008. Are Social Networking Sites Growing Up?. IEEE Distributed Sys-tems Online, 9(2), pp.3-3. https://doi.org/10.1109/MDSO.2008.4

[31] Tisserant, E., Bessard, L. and de Sousa, M., 2007, June. An open source IEC 61131-3 integrated development environment. In Industrial Informatics, 2007 5th IEEE Inter-national Conference on (Vol. 1, pp. 183-187). IEEE.

[32] Cheng, L.I., Basu, A. and Goebel, R., 2009. Interactive Multimedia for Adaptive Online Education. IEEE MultiMedia, 16(1), pp.16-25. https://doi.org/10.1109/MMUL.2009.11

[33] Fouser, R.J., 2010, July. From CMS to SNS: Exploring the use of Facebook in the so-cial constructivist paradigm. In Applications and the Internet (SAINT), 2010 10th IEEE/IPSJ International Symposium on (pp. 221-224). IEEE.

[34] Li, H.H.S., Yang, Z., Lv, Q., Han, R.I.R.R. and Mishra, S., 2014, December. A compari-son of common users across instagram and ask. fm to better understand cyberbullying. In Big Data and Cloud Computing (BdCloud), 2014 IEEE Fourth International Con-ference on (pp. 355-362). IEEE.

[35] Kontaxis, G., Polakis, I., Ioannidis, S. and Markatos, E.P., 2011, March. Detecting so-cial network profile cloning. In Pervasive Computing and Communications Work-shops (PERCOM Workshops), 2011 IEEE International Conference on (pp. 295-300). IEEE.

[36] Kirlappos, I. and Sasse, M.A., 2012. Security education against phishing: A modest proposal for a major rethink. IEEE Security \& Privacy, 10(2), pp.24-32. https://doi.org/10.1109/MSP. 2011.179

[37] Abbattista, F., Calefato, F., Gendarmi, D. and Lanubile, F., 2008, September. Incorpo-rating social software into distributed agile development environments. In Proceed-ings of the 23rd IEEE/ACM International Conference on Automated Software Engi-neering (pp. II-46). IEEE Press. 
[38] Lee, B.G., Bregni, S., Desmond, C. and Pape, J., 2011. Education, training and certification: disseminating COMSOC's technological assets [The President's Page]. IEEE Communications Magazine, 49(8), pp.6-9. https://doi.org/10.1109/MCOM.2011.5978405

[39] Faraon, M. and Kaipainen, M., 2014, August. Much more to it: The relation between Facebook usage and self-esteem. In Information Reuse and Integration (IRI), 2014 IEEE 15th International Conference on (pp. 87-92). IEEE.

[40] Weinman, J., 2016. Hybrid cloud economics. IEEE Cloud Computing, 3(1), pp.18-22. https://doi.org/10.1109/MCC.2016.27

[41] Wang, S.M. and Hou, H.T., 2014, July. Exploring Learners' Cognitive Processing Be-havioral Patterns of a Collaborative Creativity Project Using Facebook to Support the Online Discussion. In Advanced Learning Technologies (ICALT), 2014 IEEE 14th International Conference on (pp. 505-507). IEEE.

[42] Alhazmi, A.K., Rahman, A.A. and Zafar, H., 2014, December. Conceptual model for the academic use of Social Networking Sites from student engagement perspective. In e-Learning, e-Management and e-Services (IC3e), 2014 IEEE Conference on (pp. 1-6). IEEE.

[43] Terrana, D., Augello, A. and Pilato, G., 2014, June. Facebook users relationships anal-ysis based on sentiment classification. In Semantic Computing (ICSC), 2014 IEEE In-ternational Conference on (pp. 290-296). IEEE.

[44] Lin, K.M., 2015, July. Understanding undergraduates' information literacy from their Facebook usage. In Advanced Learning Technologies (ICALT), 2015 IEEE 15th Inter-national Conference on (pp. 256-257). IEEE.

\section{Authors}

Rozhgar Dhyab is from Iraq who is pursing his master study in field of Software Engineering at Firat University in Turkey. His research interess is in software engineering, cyber security, networking and social networks.

Asaf Varol is a full time professor at Firat University in Turkey and he is the chair of Software Engineering Department at College of Technology. His research interests are cyber security, distance education, analysis of pattern recognition, robotics, networking, etc. He is the founder of the Department of Digital Forensics at Firat University which is still first and unique in Turkey. He have published more than 18 books, and more than 300 articles and proceedings. His native language is Turkish and he can also speak German and English fluently.

Article submitted 12 August 2018. Final acceptance 23 October 2018. Final version published as submitted by the authors. 